\title{
Intramuscular Hemangioma of the Masseter: Erectile Hemangioma
}

\author{
${ }^{1}$ Vikash Jain, ${ }^{2}$ Nandini Bahri, ${ }^{3}$ Hiral P Parekh, ${ }^{1}$ Swati S Mody \\ ${ }^{1}$ Senior Resident, Department of Radiodiagnosis, MP Shah Medical College, Jamnagar, Gujarat, India \\ ${ }^{2}$ Professor and Head, Department of Radiodiagnosis, MP Shah Medical College, Jamnagar, Gujarat, India \\ ${ }^{3}$ Associate Professor, Department of Radiodiagnosis, MP Shah Medical College, Jamnagar, Gujarat, India
}

Correspondence: Vikash Jain, Senior Resident, Department of Radiodiagnosis, MP Shah Medical College, Jamnagar, Gujarat India, e-mail: vikashrjain007@gmail.com

\begin{abstract}
Intramuscular hemangiomas are rare benign congenital neoplasms of vascular origin. They account for less than $1 \%$ of all hemangiomas and less than $20 \%$ of these are found in head and neck and present in 2 nd and 3rd decade. The masseter is the most frequently involved site in the head and neck. Because of their infrequency, deep location and unfamiliar presentation, these lesions are seldom correctly diagnosed clinically and usually present as facial swelling causing facial asymmetry. A case of intramuscular hemangioma occurring in masseter muscle of an 8-year-old girl is presented here. Ultrasonography, color Doppler and Gd-enhanced MRI were performed and a presumptive diagnosis of hemangioma was considered which was subsequently confirmed by excision biopsy.
\end{abstract}

Keywords: Hemangioma, Benign vascular neoplasm, Intramuscular, Masseter.

\section{INTRODUCTION}

Intramuscular hemangiomas are uncommon benign vascular neoplasms of the head and neck occurring mainly in adults and are usually asymptomatic until growth spurt occurs and present in 2nd and 3rd decade of life. Head and neck hemangiomas are usually located in theregion of themasseter muscleand parotid gland. ${ }^{1}$ Intramuscular hemangiomain the masseter muscle is also known as erectile hemangioma because it bulges when a patient chews. ${ }^{2} \mathrm{U}$ nlike infantile cutaneous capillary hemangiomas, they do not regress spontaneously and their deep location and unfamiliar presentation may cause a diagnostic dilemma. ${ }^{3}$ Differential diagnosis is usually based on benign clinical course, noninflammatory presentation, age, site and imaging appearance.

\section{CASE REPORT}

An 8-year-old girl was found with facial swelling and asymmetry during School Health Program and was referred to our institute. She was otherwise asymptomatic. On examination, a soft, noninflammatory, painless lesion of size approx. $(2 \times 2) \mathrm{cm}$ was found on the right cheek which had apparently been present since the last 3 years. The lesion was found to become prominent on clenching teeth (Figs $1 \mathrm{~A}$ and B). Oral cavity examination was unremarkable. Ultrasound showed a lobulated, hypoechoic mass lesion (Fig. 2) involving right masseter muscle with evidence of color flow on Doppler examination (Fig. 3).

The maxillofacial magnetic resonance imaging was performed on 1.5 Tesla Siemens M agnetom Essenza. The

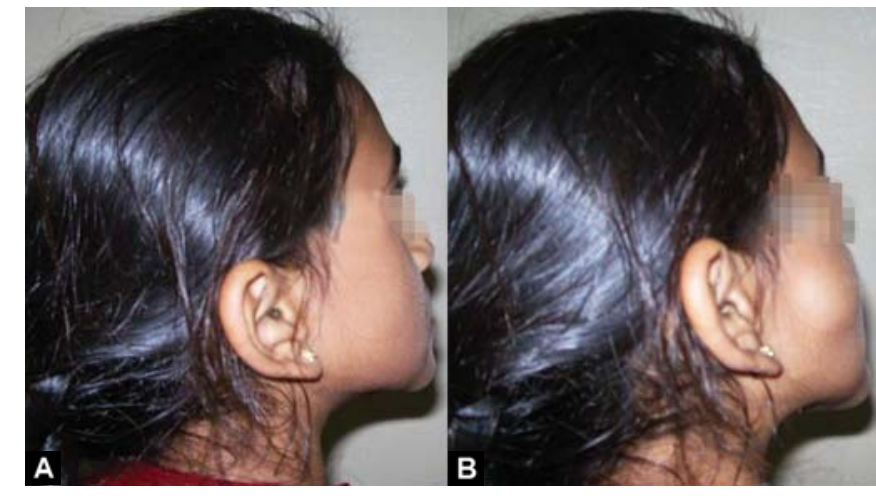

Figs 1A and B: (A) Mild facial asymmetry, (B) asymmetry accentuated on clenching teeth

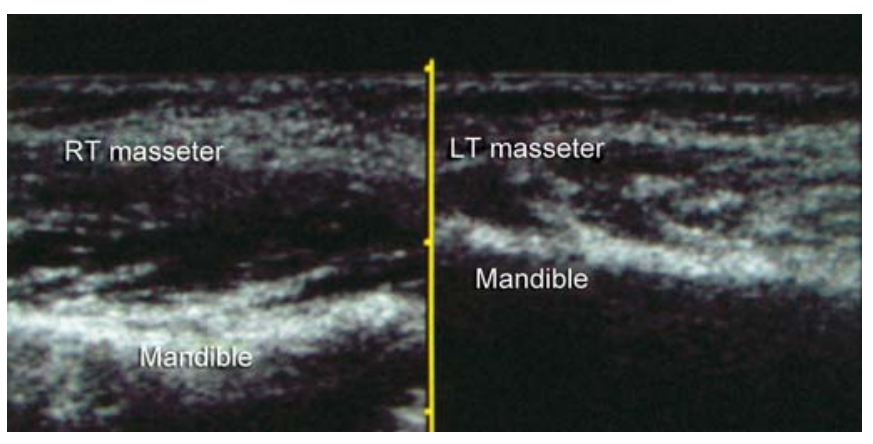

Fig. 2: Gray scale USG shows asymmetry in size of both masseters with right masseter showing heterogeneous, predominantly hypoechoic lesion

study revealed a lobulated lesion involving the right masseter and extending into the buccal space anteriorly. The lesion was isointense on T 1WI, inhomogenously hyperintense on T2WI and PD images (Figs 4A and B). 


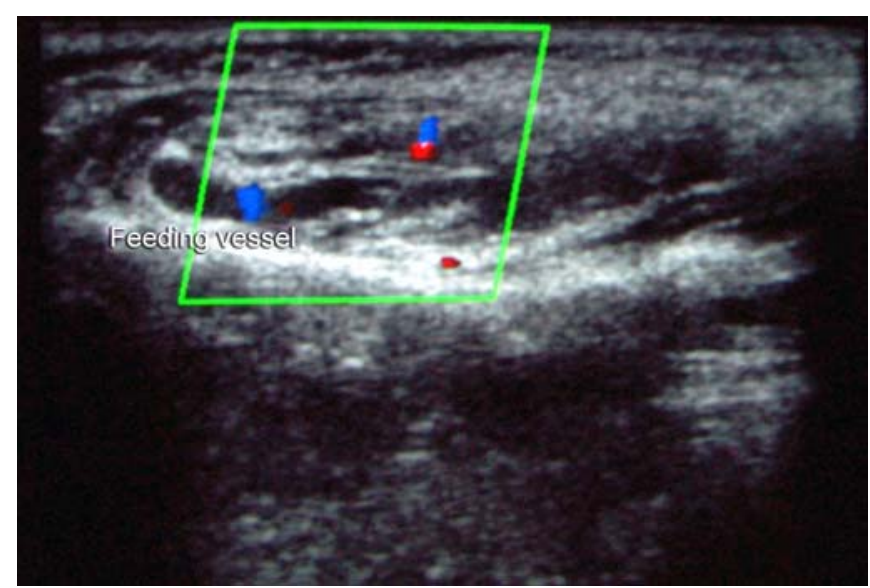

Fig. 3: Color Doppler sonography showing internal vascularity


Figs 4A and B: (A) Coronal T1W1 showing isohypointense lesion, (B) coronal PD, axial T2 and T2 fat sat. Images showing hyperintense lesion

FNAC was performed, showing the presence of hemorrhagic specimen.

A presumptive diagnosis of hemangioma was considered and because of the cosmetic deformity, patient's parents were keen on surgical correction. The tumor was resected with an extraoral approach. Feeding vessels were ligated. The tumor was removed without causing facial nerve palsy or parotid duct obstruction. The biopsy report showed findings suggestive of cavernous hemangioma.

\section{DISCUSSION}

Hemangiomas are benign proliferative vascular lesions characterized by increased endothelial cell turnover. They usually appear after birth, grow rapidly and involute over the years. Within the spectrum of vascular lesions, intramuscular hemangiomas are very rare, accounting for less than $1 \%$ of all hemangiomas and the masseter is the most frequent muscle, accounting for $5 \%$ of all intramuscular hemangiomas. Other frequently involved muscles are trapezius, extraocular muscles, sternocleidomastoid and temporal is.

They are nonmetastasizing benign congenital tumors that, after remaining unrecognized for long periods, may suddenly start to grow in the 2nd or 3rd decade of life and usually present as pal pable, fluctuant or firm mass in up to $98 \%$ of cases.

The diagnosis of intramuscular hemangiomas requires a high index of suspicion. Whenever a soft tissue density is encountered in the region of skeletal muscle in a young adult, hemangioma should be considered in the differential diagnosis. I maging is valuable in cases of deep hemangiomas with normal overlying skin and in case of clinically atypical soft tissue masses.

On plain X-rays and CT scan, phleboliths and calcifications can sometimes be identified but they may nonspecific. Ultrasonography is the first-line imaging procedure for patients with soft tissue swellings. Presence of color D oppler signal in a well-defined hypoechoic mass with heterogenous echotexture in the head and neck region should raise the possibility of hemangioma. ${ }^{4}$

M RI is more reliable in detecting and delineating deep seated and large intramuscular hemangioma which shows intermediate signal on T1WI and hyperintense signal on T2W I with strong postcontrast enhancement. The marked hyperintensity on $\mathrm{T} 2 \mathrm{WI}$ images is related to the increased free water present within the stagnant blood found in the larger vessels of this lesion. Low-signal linear structure represents fibrofatty septa between vessels. A ngiography might not be able to establish the diagnosis due to slow flow but can assist in planning the surgical approach. ${ }^{5}$

FNAC usually shows the presence of hemorrhagic specimen and is commonly nondiagnostic but helps in exclusion of other soft tissue tumors and can be a supportive investigative tool. ${ }^{4}$

L ymphatic mal formation and arteriovenous mal formation (A V M ) are the usual differential diagnosis. Lymphatic mal formations are presentfrom birth and are usually detected by the age of 2 years. On MRI, Iymphangiomas are nonenhancing as opposed to the intensely enhancing hemangiomas. ${ }^{6} \mathrm{H}$ emangioma with arterial flow can bedistinguished from AVM by the presence of solid parenchymal tissue.

Intramuscular hemangioma should al ways be considered in differential diagnosis of isolated muscle enlargement in a patient presenting with soft, fluctuant, painless lesion. Color Doppler sonography and M RI are very helpful in its diagnostic work-up. ${ }^{4}$

\section{REFERENCES}

1. Chatrath P, Pfleiderer A G, Blundell JW. A rare case of intramuscular hemangioma in a six-year-old boy-a diagnostic dilemma. J Laryngol Otol 1998;112(12):1181-82. 
2. Takuya Takahashi (Y okohamashishiminbyoin K eiseigeka), Hirotatsu Shibata (Y okohamashishiminbyoin K eiseigeka), M ori $M$ ari (Y okohamashishiminbyoin K eiseigeka), et al. A case of intramuscularhemangiomain masseter muscle. O tolaryngologyHead and Neck Surgery (Tokyo) 2003;75(1):39-43.

3. Zühtü Demir, Fatih Öktem, Selim Celebioglu, et al. Rare case of intramasseteric cavernous hemangioma in a three-year-old boy: A diagnostic dilemma. The A nnals of O tology, R hinology and Laryngology 2004;113(6):55-458.
4. Afsar Fatma Sule, Oziz Ergun, Hamdioglu Yalcin, et al. Intramuscular hemangioma of the masseter muscle in a 9-yearold girl. A cta A ngiologica 2007;13(1):42-46.

5. Buetow Peter $C, K$ ransdorf $M$ ark J, Richard P M oser Jr, et al. Radiologic appearance of intramuscular hemangioma with emphasis on M R imaging. AJR 1990;154:563-67.

6. Y onetsu $\mathrm{K}, \mathrm{N}$ akayama $\mathrm{E}, \mathrm{K}$ awazu $\mathrm{T}$, et al. V alue of contrastenhanced magnetic resonance imaging in differentiation of hemangiomas from lymphangiomas in the oral and maxillofacial region. Oral Surgery, Oral M edicine, Oral Pathology, Oral Radiology, and Endodontics 1999;88(4):496-500. 